\title{
Death in Venice and the Aesthetics of Sublimation
}

We got into the auditorium, Julian now pulling me, and found our seats, half-way back in the stalls. People stood up to let us in. I hate this. I hate theatres. There was an intense subdued din of human chatter, the self-satisfied yap of a civilized audience awaiting its "show": the frivolous speech of vanity speaking to vanity. And now there began to be heard in the background that awful and inimitably menacing sound of an orchestra tuning up. ${ }^{1}$

-IRIS MURDOCH, THE BLACK PRINCE (1973)

At the crux of Iris Murdoch's The Black Prince (1973) stands a musical orgasman "operatic" gesture that resounds throughout the novel. From the overture to Strauss's Der Rosenkavalier, it is doubtless familiar to Covent Garden regulars. Yet this sound is related by Bradley Pearson, a self-styled highbrow who would not ordinarily be found in such vulgar company. The only reason he is there is because he was invited by Julian Baffin. In accompanying this young girl to the Royal Opera House, Pearson reveals the depth of his infatuation; for him, a night at the opera represents a prospect more daunting than hell. ${ }^{2}$ Indeed, operatic spectacle is the only thing worse than the trashy novels that Julian's father churns out. Even as it draws on the lewd and inane, opera apparently harbors pretensions to greatness and sublimity. As he takes his seat in the stalls, he can only imagine the high-minded rhetoric to which this bourgeois audience will turn, once the interval drinks arrive, in order to sublimate opera's "cheap" thrills and mindless entertainment.

As it turns out, Pearson does not even make it that far, for Strauss's gaudy fare proves literally impossible for him to stomach. While the prelude makes him writhe in his seat, the love scene has him throwing up in the nearest alley. Yet despite Pearson's contempt, this reaction results as much from pleasure as from pain, with his uncontrollable urge to vomit serving none too subtly as a metaphor for sexual release. Neither is this the first nor the last time that Pearson is delivered into erotic frenzy. For all that he fancies himself a modern-day Apollo, an ascetic 
man of letters and paragon of moral virtue, he seems to have little self-control. Throughout the first half, he struggles to impose order on his rampant sex drive. After an illicit affair with Rachel Baffin, he turns his affections to her young daughter, drawing on all the Platonic clichés he can muster to sublimate his desires. The only difference between the opera audience's ponderous platitudes and his own is that theirs succeed where his fail. Where they are able to maintain an air of decorum, Pearson is set on a downward spiral into the Dionysian abyss, as he takes the young and innocent Julian to his bed.

In thematizing the gulf between the highbrow's lofty words and his prurient deeds, Murdoch's novel suggests that cultural boundaries were more a matter of sublimation than of essence. Nevertheless, if The Black Prince shines a light on this process of translating art's disreputable pleasures into intellectual reflection, it reflects back onto Murdoch's novel itself. ${ }^{3}$ Notwithstanding all the ironizing techniques, the book and its readers are implicated in the aesthetic of sublimation it diagnoses. Even as the tale teems with "lowbrow" preoccupations-sex, slapstick humor, contrived narrative twists, and melodramatic thrills-it shrouds them in the highbrow intellectualisms and abstractions that were supposedly the stuff of high art. While this mixture of intellect and sensation endeared Murdoch's stories to late-twentieth-century readers, criticism has rarely been so balanced. Apparently unable to resist the philosophical nattering, commentators have ignored their more immediate pleasures. ${ }^{4}$ To treat such high-minded "novels of ideas" as one would most other fiction of the period would apparently be to risk seeming narrowly literal, if not crude. Much like the operas it vilifies, The Black Prince offers its readers deniability: the chance to revel in the "cheap" pleasures of popular fiction while simultaneously disavowing them.

In the same year that the fictional Pearson was invented, Gustav von Aschenbach, one of his close relatives, was resurrected in Britten's Death in Venice (1973), an opera based on Thomas Mann's novella from 1912. Like Pearson, Aschenbach is an aging novelist and intellectual who, in the midst of a bout of writer's block, turns his attention to an adolescent, this time a young Polish boy holidaying with his family on the Venetian Lido. He too summons all the philosophical wisdom he can muster in order to control and rationalize his infatuation, but his sublimation proves unsuccessful and he succumbs to his bodily desires. Britten's opera resembles The Black Prince in form as well as content, for it is similarly fragmented, broken up into passages of spectacular melodrama and abstract philosophical monologues, which meditate self-consciously on foundational aesthetic oppositions.

Just as telling were the parallels in how the two works were received. The reception of Britten's opera appears to have replicated the aesthetic of sublimation staged as its subject matter. In a review of the first production, John Robert-Blunn parodied this high-minded response in a vignette strongly resembling Murdoch's opera scene: 
"Intense intellectual approach to the emotions," said one young man gaily, to another, after experiencing Benjamin Britten's new opera Death in Venice at the King's Theatre, Edinburgh, last night ... When everyone else can see the Emperor's new clothes, I feel that I should be able to see them, too. But I can't. This gripping English Opera Group production ... has many merits, but there seem to be so many messages to be understood or misunderstood. In a long introduction for the likes of me, Andrew Porter discussing Mann's novel (on which Myfanwy Piper's libretto is based) writes: "The story, dealing with art and life, . . is a complex and many-layered composition. So is Britten's opera." The art of understatement is not dead. ${ }^{5}$

Like Pearson, Robert-Blunn was troubled by the discrepancy between the work's idealistic reception and its less-than-ideal spectacle, which included "a bit too

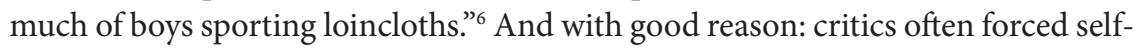
conscious gaps between the opera and its interpretation, warning audiences that there was more to the opera than meets the eyes and ears. "It's not only what happens," John Amis insisted, "but why and how and what passes through the mind of Aschenbach that makes the story interesting."7 Roger Baker went even further, dismissing literal interpretations as ignorant: "Those who hadn't done their homework could be forgiven for seeing him as a cruising predator but it is, of course, a mistake to see Death in Venice as an opera about a homosexual situation." Martin Cooper came closer still to Robert-Blunn's highfalutin critical stereotype:

The subject of Britten's "Death in Venice," which had its first performance at the Maltings at Aldeburgh on Saturday night, is the artist's nature and, in a profounder sense than Strauss's "Capriccio," the nature of art itself. In Myfanwy Piper's libretto the different levels of Thomas Mann's story are skillfully dramatised ... The boy Tadsio [sic] is no more than an agent, and in Mann's story the sex is almost irrelevant. ${ }^{9}$

Cooper was just one of many to reference the different hermeneutic "levels" to which the opera was susceptible, arranging them in such a way as to render the most immediate unmentionable in anything other than a negative sense. ${ }^{10}$ To read Britten's opera as a tale of erotic infatuation, in other words, was to misread it. Yet, for all that early critics warned of the likelihood of narrowly sexual interpretations, such readings remained conspicuous by their absence.

With most critics following Aschenbach in "spouting pondering platitudes about art and life and the creative artist," it fell to queer theorists, almost twenty years later, to point to the elephant in the room. In 1994, Philip Brett identified "allegorization" as the method by which the powerful, unequivocal homoeroticism of Death in Venice was neutralized. It was, he suggested, as part of a concerted effort to keep the composer closeted that "music critics fell over themselves to adopt and elaborate upon the Apollonian/Dionysian allegory with which Mann himself had clouded some central questions." ${ }^{11}$ While Brett was right to stress that the dominant mode of reception had served to "mask, parry, or render ridiculous [its] homosexual content," this was only one symptom of a much broader selectivity. 
Unlike Brett, I view the response to Death in Venice as formed not only by the epistemology of the closet but also-like the other operas discussed throughout this study-by the logic of the "great divide." It was this logic that propelled Pearson's snobbery, compelling him to reject all but the most difficult and intellectual artworks as "mere" entertainment. It was also what moved Murdoch's devotees to their own selective readings. If the novel so uncomfortably straddled the great divide that it could only be rescued by the most abstract of philosophical meditations, the position of opera in the 1960s and 1970 s was more precarious still. Not only fictional intellectuals like Pearson but a large number of critics regarded opera as one of the lowest artistic forms, denigrating it as both unseemly and unviable in the twentieth century.

Death in Venice's reception reflects this context, relying as it did on the stock oppositions of contemporaneous anti-operatic discourse: between abstraction and immediacy, the intellectual and the visceral, form and rhetoric. In styling the opera's charms as more intellectual than visceral, there was a lot a stake. Critics were attempting to secure not just Britten's place on the "right" side of the divideas we have seen time and again-but also that of the genre more broadly. Yet they were never able to erase fully the opera's powerful spectacles and visceral music, making for a reception just as full of defensiveness, ambivalence, and contradiction. Like the other operas examined hitherto, Death in Venice invited precisely the selectiveness it resisted. At once staging and confounding oppositions at the heart of operatic criticism, Death in Venice shows how composers, directors, critics, and audiences responded to opera's troubled twentieth-century reputation.

\section{STAGING ABSTRACTION}

When, almost forty years ago, audiences began to chuckle about Lohengrin's swan and the Germanic beards in the Ring... [o]ne sensed that, artistically, things just could not go on like this, that this very stylization was making opera into a marketable specialty item. The music of Figaro is of truly incomparable quality, but every staging of Figaro with powdered ladies and gentlemen, with the page and the white rococo salon, resembles the praline box, not to mention the Rosenkavalier and the silver rose.

- T. W. ADORNO, “OPERA AND THE LONG-PLAYING RECORD” (1969) ${ }^{12}$

As scholars have often observed, the twentieth century was a troubled time for opera; when not being denounced as a bastion of elitism, it was charged with prefiguring "some of the worst abominations" of the culture industry. ${ }^{13}$ Yet even so, the late 1960s and early 1970s represented a real low point. In the same year that Peter Brook denounced opera as the embodiment of everything wrong with the theater, Pierre Boulez recommended that opera houses be blown up. ${ }^{14}$ This last suggestion caught the imagination of the British music press; after reprinting 
the original article in translation, Opera debated the modern opera "problem" in depth. ${ }^{15}$ "When I go to a performance now," Boulez elaborated:

I ask myself why are they singing! I feel too a contradiction between the convention of opera, which is pure convention, and the realistic gestures of singers, which are conventional in the bad sense ... When I see the Japanese Nõ theatre or Banraku [the puppet theater], each of which is still more conventional, more stylized than opera, it is all so far away from realism that I am not disturbed at all. What I don't like in opera is the perpetual reference to the world of everyday. ${ }^{16}$

Echoing a critique already voiced by Bertolt Brecht in the 1930s, Boulez's explanation would appear to confirm that anti-operatic sentiments were united in opposition to the realistic traditions of the nineteenth century. ${ }^{17}$ However, while some lamented opera's aspirations to realism, others bemoaned the stylization that Boulez advocated. After complaining of "artificiality" in the epilogue to Opera: A Modern Guide, Arthur Jacobs and Stanley Sadie diagnosed "widespread impatience with a form so stylized" in their postscript from 1969 to the same publication. ${ }^{18}$ Writing elsewhere the same year, Jacobs appears to have shouldered the burden of opera's contradictions as he denigrated the genre for being both too realistic and not realistic enough. ${ }^{19}$

If such criticisms appear paradoxical, Jacobs's prescriptions offer some clarification. According to him, it was the "gramophone record" that heralded the way forward, offering scope for a "music theatre of the mind," "untrammelled by theatrical compromise, untroubled by singers' difficulties in withstanding the orchestra, unconcerned with the audience's sight-lines or drinking habits." ${ }^{20}$ In casting technology in the role of deus ex machina, Jacobs echoed the sentiments of Adorno's "Opera and the Long-Playing Record," published just eight months earlier. ${ }^{21}$ After complaining of a mode of reception that focused on the minutiae of operatic production, Adorno asked: "What's the point? Why even bother doing it on stage? One wants to spare Mozart from this." ${ }^{22}$ For Adorno, no less than for Jacobs, the long-playing record promised to force "concentration on music as the true object of opera . . comparable to reading, to the immersion in a text." ${ }^{23}$ Implying that opera would be better served without live performance's material distractions, these accounts suggest that the "problem"-while often framed as a question of realism versus stylization-ran deeper, indicating wider suspicions of the genre's flagrant materiality. As Martin Puchner has suggested, modern anti-theatricalism drew on much older idealistic traditions. ${ }^{24}$ The "problem," in other words, was as much a question of reception as of production; whether reveling in the details of magnificent mise-en-scène or enjoying the empathy of realistic representation, audiences were deemed to be stuck in Plato's cave.

Far from delivering the final nail to opera's coffin, this crescendo of antioperatic discourse coincided with a revival of interest in opera and music theater. While some composers, such as Nicholas Maw, Richard Rodney Bennett, 
and Malcolm Williamson, continued to produce relatively traditional, large-scale operas, an even greater number attempted to remedy the maladies that detractors diagnosed. ${ }^{25}$ Britten occupied a precarious place along this aesthetic divide. From a relatively early age, he acknowledged the need to modernize even while composing works that kept operatic traditions alive. As early as 1944, while still at work on his first and most "realistic" opera, Britten lamented the paradoxes of operatic realism using precisely the terms Jacobs and Boulez would employ more than twenty years later: "I feel that with the advent of films, opera may turn its back on realism, and develop or return to stylization-which I think it should. It is an art and it should be 'artificial,' for, after all, people don't usually use singing as their usual method of communication in real life." ${ }^{26}$ When he later turned his attention to more experimental forms of drama, he framed them as long-awaited solutions to opera's "problem." ${ }^{27}$

As we learnt in the previous chapter, Curlew River (1964) and the other church parables represented his most sustained attempt to construct a "drama of ideas." In fusing elements of Japanese Noh theatre with Christian liturgy, they mobilized ritualistic representation to encourage a reception more symbolic than literal. ${ }^{28}$ As the producer Colin Graham made clear, the aim was, above all, to avoid "theatrical effects": "The movement and production details should be as spare and economical as possible; the miming, which plays an integral part, is symbolic and should be pared down to its quintessence." 29 In addition to heavy restrictions on gesture, Graham eschewed the extravagant set designs that Adorno and others decried. It was doubtless Curlew River that Sadie and Jacobs had foremost in mind when they wrote:

That Benjamin Britten has written some operatic works which are not for the operahouse at all is symptomatic of the suspicion with which many composers of different countries have viewed the old-fashioned operatic form and conservatively-inclined managements and audiences of established opera houses. ${ }^{30}$

On the other side of Britten's operatic equation, and even more than Owen Wingrave (1971), Death in Venice appears to have signaled a return to a more traditional form of opera: not only was it written for an opera house but it also reverted to a larger and more conventional orchestra than the church parables. Nevertheless, as commentators have often emphasized, the composer's operatic swansong absorbed many of the anti-operatic characteristics of the works that preceded it. ${ }^{31}$ It shared directors with the church parables, thus emerging with several similarities of mise-en-scène. Although Graham's original intention to "entirely do away with the straight-line stage \& the proscenium" was thwarted, the production still sought to avoid resembling traditional theater: "it's a totally unrealistic approach, in fact, scenically, and it's a very cerebral piece, and we've tried to devise a way of designing that is rather like a camera-the inside of a camera-a man's mind, with images growing out of the darkness and retreating into it." ${ }^{32}$ In seeking 
to dematerialize the Venetian setting, Graham even followed Jacobs and Adorno in turning to technology:

It won't be really until we get to Covent Garden that we will be showing the piece entirely as we want to show it because we'll be able to put up a lot of back projections there, whereas here at Snape, we've had to put a gantry where we can use five or six separately backlit backcloths instead of the twenty five or so projections that we'll be able to use later on. ${ }^{33}$

Apparently even more remarkable than the use of backlit backcloths was the extreme economy of means: through most of the production, very little attempt was made to draw audiences into a scenic illusion. Recalling the minimalism of the church parables, there was often little more to sustain visual interest than the downstage protagonist set against a black backdrop (see Fig. 14). William Mann praised "Colin Graham's spare, pointed, highly theatrical production which conjures marvels from black drops and a few people," while Edward Greenfield lauded the "restraint [which] may be judged in that only after 50 minutes does John Piper's full Venetian canal-scape emerge for the first time, swiveled into view on enormous triangular columns." ${ }^{34}$

Although some backdrops gestured toward a realistic sense of place, most of Piper's set designs followed the minimalist aesthetic that Graham had described. With the exception of Greenfield, critics got the point. Martin Cooper praised "John Piper's spare but evocative scenery," while John Falding reported: “The opera lasts more than two and a half hours, but its two acts contain 17 scenes which designer John Piper achieves mainly through backlit paintwork and photographs. We are kept to the barest essentials." ${ }^{35}$ Nor was this minimalism's significance lost on them. Even the most conservative of commentators, lamenting that the "black, depressing set creates no illusion of the splendour of one of the world's most beautiful cities", admitted: "if Death in Venice is an illusion imprisoned in Aschenbach's imagination, perhaps the set is perfectly illustrative." ${ }^{36}$

Far from limited to the opera's staging, however, this anti-literalism was fundamental to all aspects of the opera's conception, as Greenfield pointed out. One of the ways, he explained, that Britten and Piper sought to "enhance the symbolic elements" was by "having a single singer take on the incidental parts." ${ }^{37}$ On the most basic level, this allowed the creators to undermine the direct association between individual performers and specific characters, contradicting a key tenet of dramatic realism. However, it also allowed them to flesh out, quite literally, these characters' symbolic roles as representations of fate. According to Cooper, this dramaturgical technique marked them as Dionysian impulses within the protagonist himself:

By giving seven of the smaller roles to a single singer (John Shirley-Quirk) and thus suggesting their single identity, Britten emphasises the existence of a Kafkaesque plot against Aschenbach, finally revealed when the listener recognizes in the voice of Dionysus those of the Traveller, Fop, Manager, Barber and Leader of the Players. ${ }^{38}$ 


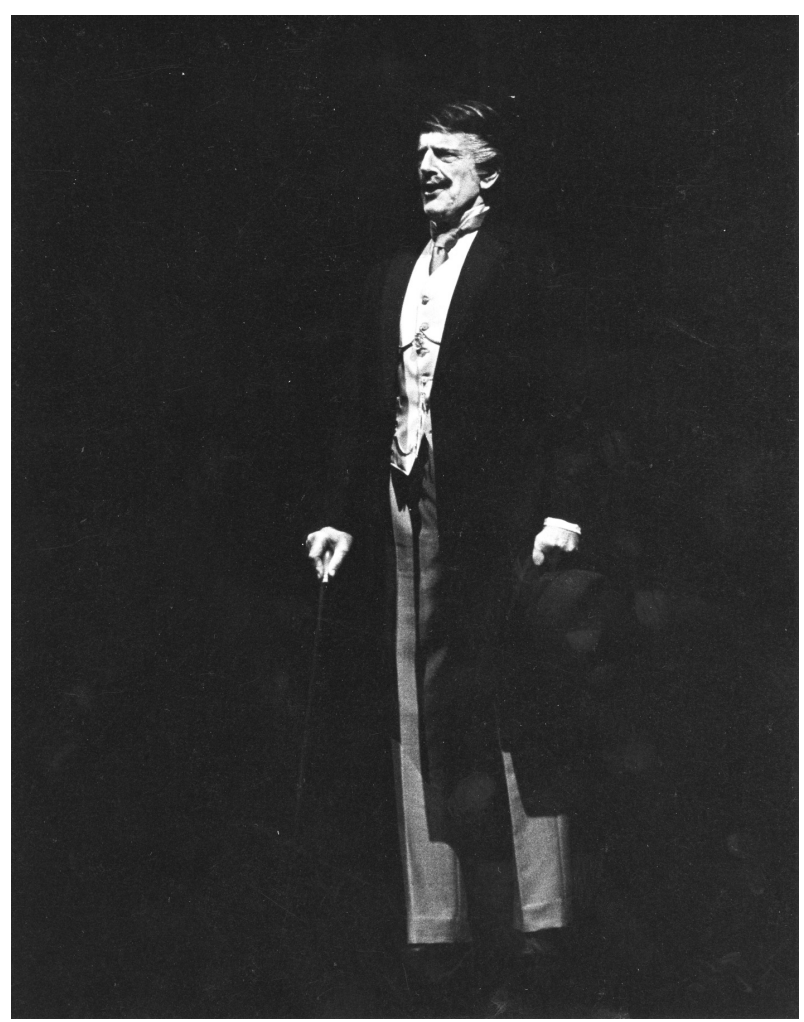

FIG. 14. Death in Venice (Act I, Scene 1)-Aschenbach (Peter Pears), Snape Maltings, Suffolk, June 1973. Photo: Nigel Luckhurst. Image reproduced courtesy of the Britten-Pears Foundation.

In casting the Polish family as mute dancers, the creators added another level of separation to this "complex and many-layered composition." ${ }^{39}$ For Ned Rorem, writing for The New Republic, this dramaturgical decision was the only responsible reading of the novella's symbolism: "If the Silent Ideal must be depicted within a medium whose very purpose is noise, then mime, while a bit illegal, is probably the only solution."40

According to Greenfield, an even more forceful way of encouraging abstract readings was through dramatic minimalism - a dearth of action - to parallel the abstemiousness of the staging. In banishing the kind of narrative events associated with traditional drama, the creators forced audiences to dig for "deeper" symbolic levels. As Kenneth Loveland explained:

Even in the most dramatic operas, such as Peter Grimes and Billy Budd, Britten is concerned with mental plight, and no matter how widespread the background, the focal 
point is often narrowed down to man's inner conflict with himself ... Here [in Death in Venice], to achieve what is essentially an examination of introspection, Britten reduces the opera to almost a personal narration; it is von Aschenbach we hear, and very nearly everything that happens is a musical or visual representation of his thoughts. ${ }^{41}$

Loveland was not the only critic eager to grasp this significance: while Stephen Walsh concluded that "Aschenbach is not merely the hero of the story: he is the story," Jeremy Noble explained that "the bald formality with which Aschenbach announces his preoccupations ... takes a little getting used to as a convention but proves not inappropriate for so initially stiff and detached a figure." 42 "The actual incidents of the story," he continued, "are seen merely as an intermittent background to the ceaseless reflective monologue." After admitting "in at least three of Britten's earlier operas the action is surrounded by an element of separate commentary in the form of prologues and epilogues," Bayan Northcott lauded the monologue's originality: "I can think of no operatic precedent for the almost complete reversal of traditional narrative priorities in Death in Venice." 43

The desire to coerce a more abstract appreciation of the work was as palpable in the monologue's content as in its form. In its patchwork of philosophical aphorisms, the opera wore its intellectualism proudly, as Robert-Blunn noted caustically: "in the course of the opera's 17 deftly changing scenes . . Aschenbach emerges as a pompous twit, spouting ponderous platitudes about art and life and the creative artist." 44 Despite his vitriol, Robert-Blunn was not altogether wrong. In addressing abstract intellectual questions, Death in Venice formed part of a wave of "philosophical operas," designed to reinvent opera as a cerebral genre. In reflecting on artistic representation, moreover, it gestured toward the "artist opera," a notable subgenre of this broader type. As Daniel Albright explains:

The philosophical opera and the opera that dissociates its media are both the products of a kind of self-consciousness ... This acute attentiveness to the problematic aspects of opera-opera's tendency to the flamboyant and fatuous-sometimes expressed itself in meta-opera, that is, opera about opera. ${ }^{45}$

Although less overt than in Ariadne auf Naxos or Capriccio, Death in Venice takes a number of self-reflexive glances at artistic process. As Cooper pointed out, it is about an aging writer and his struggle to create. ${ }^{46}$ Yet while critics and scholars have been quick to characterize the work as an "artist opera," one could just as easily describe it as an "audience opera." Aschenbach is a spectator as well as an artist. Indeed, his creations often seem to be little more than a means of sublimating his gaze. By staging the struggle and fatal failure of Aschenbach to abstract his experience, Death in Venice offered a warning to its audiences. If, as Conrad Wilson suggested, an opera "with an author as its hero" smacked of didacticism, one about a spectator did so all the more. ${ }^{47}$

Most critics heeded the less-than-subtle hints that an intellectual response was required. Although both novella and libretto speak of a Nietzschean balance 
between the Apollonian and Dionysian, the opera's reception was more one-sided, with most critics confident that Britten had managed to equal, if not surpass, the intellectualism of his source. Borrowing his terms from the opera, Andrew Porter interpreted Death in Venice as a "moral fable": whereas "Gustav von Aschenbach ... surrenders wholly, at last, to Dionysus," Mann and Britten retained a firm footing on the idealistic pedestal. ${ }^{48}$ Patrick Carnegy offered a similar opinion, albeit with a more negative spin: "Dionysus seems too much in thrall to Apollo-not least in the very well behaved choral dances." ${ }^{49}$ After observing that "the platonic element is more fully developed" in the opera than in the novella, Alan Blyth compared the "Games of Apollo" scene with Luchino Visconti's film from 1971:

Surely Visconti's vision of the visual and sensual delights of the city ... was much more convincing than anything in the opera. Venice itself, a real hotel, the period clothes, a nubile, feminine boy, even (dare I say it) Mahler's Adagietto, were so much more suggestive of the permissive decadence intended. ${ }^{50}$

In contrasting the opera unfavorably with the film, Blyth swam against the tide. For most critics, eager to praise the opera's Apollonian abstraction, Visconti's film became a negative foil. Roger Baker found that "Visconti managed to repress . . . the element which clearly makes an appeal to Britten: the intellectual control of emotion," while Peter Heyworth observed: "the vulgar simplifications that Luchino Visconti in his film imposed on Thomas Mann's wonderfully subtle and many-layered story is not calculated to appeal to a man of Britten's acute literary perception." ${ }_{51}$

Although most agreed that Britten's Death in Venice was more cerebral than Mann's, there were signs that the opera was wobbling on its idealistic pedestal. The most obvious evidence comes from dissenters like Robert-Blunn, who questioned not only the "official" interpretation but also the unanimity with which it was endorsed. Perhaps even more revealing were the denials:

In Mann's story the sex is almost irrelevant. In the opera a long choral ballet of Lidobathing youths alters the emphasis, while Aschenbach's Bacchic dream is given correspondingly less importance. In Sir Frederick Ashton's choreography erotic suggestion is muted until the very end, when Aschenbach's death reveals the Tadsio-Eros equation, beautifully suggested by Robert Huguenin's dancing. ${ }^{52}$

In his eagerness to explain away eroticism, Cooper overstepped the mark, imagining "sex" even where none exists. In suggesting that Britten elevated the "choral ballet" (otherwise known as "The Games of Apollo") over the "Bacchic dream," Cooper rehearsed the common view of the work as more intellectual than visceral. ${ }^{53}$ Cooper was not alone. Others found in the "Games of Apollo" proof of wider restrictions on sensuality in Britten's opera, praising the "poised movements" of the beach ballet as "calculated enough to be sensual without overstepping a very delicate frontier." ${ }^{44}$ While these critics located the pinnacle of the opera's idealism in "The Games of Apollo," others denounced the same scene for compromising it. 
These anxieties were already evident in the early correspondence between composer and librettist. By the summer of 1971, Myfanwy Piper struggled with a "second draft": "whereas the first beach ballet was domesticated and seaside [sic], this I think should be far more Hellenic and parodic of the idea just as Mann's language is." ${ }_{55}$ As Piper's notes made clear, the problem was how to represent the fourth chapter's stylistic contrast as a theatrical one. At this point, Mann shifts from detailed realistic narrative to a more abstract meditation on the nature of beauty, in which setting and symbol, real and ideal, become almost indistinguishable. For all its lofty prose and erudite symbolism, however, the passage contains some of the novella's most erotic writing. One suspects that it was precisely because these "moments of reality" were so sensual that the author resorted to a litany of Platonic references in order to sublimate them, drawing upon the venerable tradition of abstracting Greek love. In the context of operatic action, whereby the pederastic gaze was embodied on stage, such abstraction became at once the more difficult and the more necessary. In a letter to his librettist from May 1971, the composer showed himself all too aware of this quandary:

The scene in which I have come to a grinding halt, you know, is the big final one of Act I, the idyllic one. I couldn't get the tone right, relaxed enough after all that to-ing \& fro-ing to Venice, \& before the final climax, and abstract enough ... as if in Aschenbach's mind, and I wanted to save Aschenbach before the big set piece. ${ }^{56}$

In fashioning this scene, Britten and Piper evidently grappled with the impossible goal of staging abstraction, resisting the very materiality of the theater. For Rodney Milnes, it was not simply that their solution failed to resolve an irresolvable dilemma. In casting the opening of Mann's fourth chapter as a ballet, the composer actually compounded it:

Any external dramatic presentation ... inevitably tends to coarsen the fable, render it fleshly, mawkish even. The pitfalls are almost avoided in Myfanwy Piper's libretto, though not in the act of staging; the symbol of a twelve-year old boy on the printed page is one thing, and would be something else on stage. But a well-developed nineteen-year-old dancer is quite another, and irrelevant, matter. ${ }^{57}$

If opera's "problem" was bound up with the materiality of performing bodies, adding dance to the mix would hardly seem like the best solution. What is more, as if the exhibitionism of ballet were not already enough to make critics shake their heads in disgust, Piper considered having the dance performed naked:

I think the way to deal with the beach scenes is to have the ...2nd one [ballet], as far as the boys are concerned, really naked so as to remove the whole thing slightly from reality, as the whole of Aschenbach's attitude is removed from reality. It is a vision as well as an experience. At the end when T is mixed up with grownups he could simply have his white beach towel. ${ }^{58}$ 
Although the idea of a naked ballet was ultimately discarded for fear that "it might cause a certain interest that none of us really wants," the composer was initially receptive: "Your idea of the naked Ballet II section is excellent \& could be wonderfully beautiful, Hellenically evocative." 59 The final version of the scene was staged as a compromise, with the dancers dressed in nothing but loincloths (see Fig. 15).

Piper's and Britten's intention certainly appears paradoxical: to stage the body in order to dematerialize it; to highlight the ideal by foregrounding the real; to soften the erotic charge by stripping everybody naked. In the rarefied genre of ballet, however, this paradox had a venerable lineage, as André Lepecki has pointed out: "Historically, neither 'presence' nor 'body' are central to Western choreographic imagination . . . 'the body is suspiciously absent."'60 In turning to ballet, Britten and Piper could depend on a long tradition of abstracting bodies into concepts of form, movement, and beauty. At the same time, as Albright explains, the move risked exposing dance's voyeuristic pleasures:

A third function [of ballet in opera] might be to complement opera, to embellish the drama by doing the things that opera cannot do. Often, this entails display of the body. The premise of opera is nakedness transposed from the skin to the larynx: vulnerability, modesty, and wild abandon are all reseated in throat, all sex becomes oral sex ... But from opera's beginning, it has been understood that an audience might also enjoy seeing a copulation that was more vivid and less metaphorical than two voices in parallel thirds. ${ }^{61}$

This “risk” was intensified by Britten's and Piper's apparent desire to push sublimation to its limit. They were so eager to mark the scene as transcending the narrative world that they did not even provide audiences with a plausible dramatic pretext. Like most operatic ballets, this one is staged as an intrusion on the otherwise closed Venetian narrative as figures from Greek mythology are embodied on stage. It was in response to this precarious situation that the composer framed the ballet with a pseudo-Greek chorus:

What would your reaction be to having the "interpretations" of the boy's dances sung by the chorus as a kind of madrigal (again, your word)? Thinking of it visually, the chorus comes on at the beginning of the scene, \& group themselves round as a kind of frame-then A[schenbach] comes on and does his introduction (ending in "live in Elysium"). Then lights dim on singers, leaving the boys brilliantly lit, with $\mathrm{A}$. in the foreground. Ballet no. I followed by the chorus singing "And is that Phoebus . . . he lords in the air" either clearly visible, or in formalized groups, Aschenbach then singing "Ah, how the antique world possesses me, And everything I see prolongs the spell."62

By having the chorus chant snippets from Socratic dialogues and "interpreting" the dance as an ancient Greek pentathlon, Britten sought to dilute the scene's spectacular eroticism: by forcing home the perception that the protagonist's voyeuristic gaze was just a pretext for aesthetic reflection. 


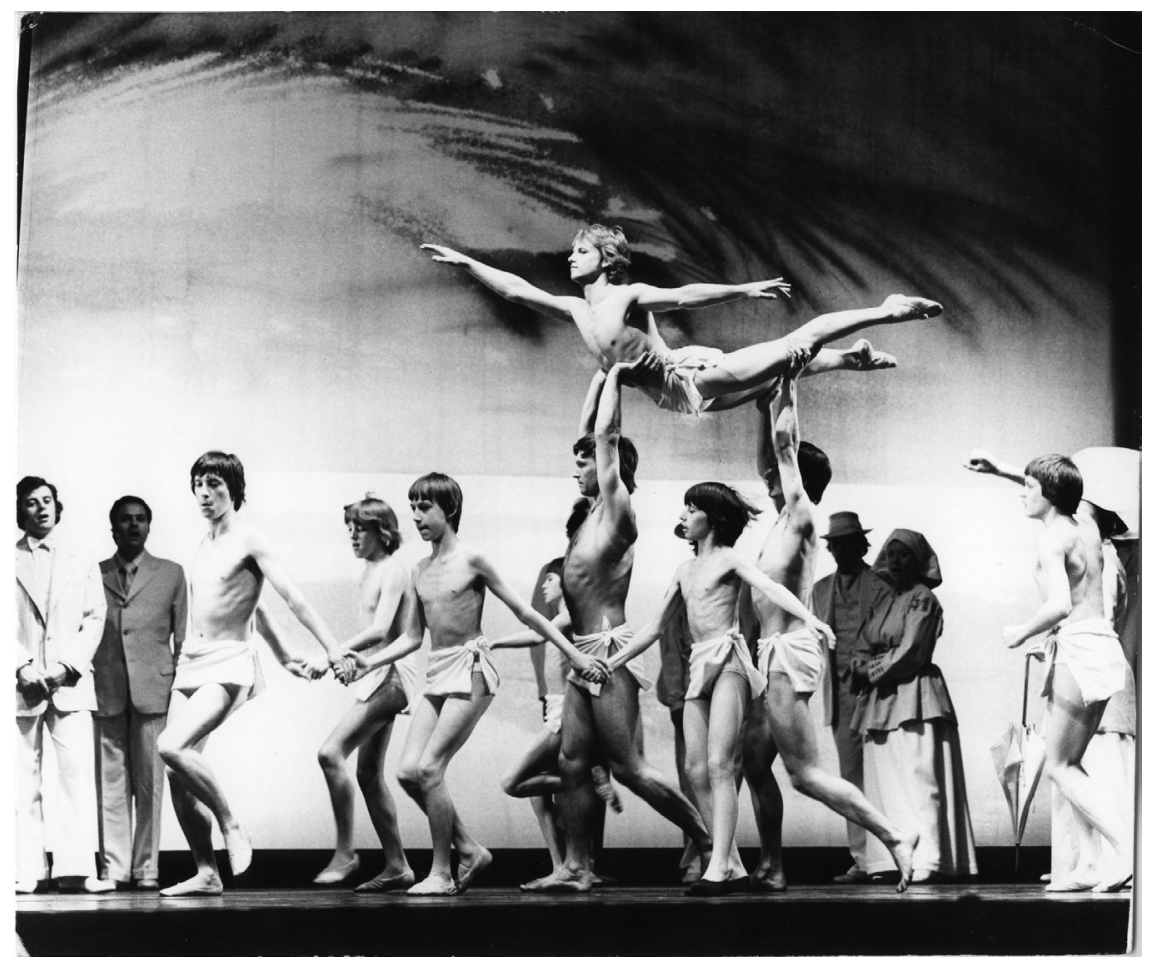

FIG. 15. Death in Venice (Act I, Scene 7)—Tadzio (Robert Huguenin) and Boys during the Games of Apollo. Snape Maltings, Suffolk, June 1973. Photo: Anthony Crickmay. Image reproduced courtesy of the Britten-Pears Foundation.

Yet for every commentator who bought this conceit there was another who expressed anxiety. Bayan Northcott's reaction was a relatively common one:

The only real disaster in this whole scheme is surely the extended children's beach ballet. Coming at the end of an Act I running an hour and a half and glorifying Robert Huguenin's rather glum Tadzio, the pre-school nostalgia of this lengthy Ancient Greek sports day strikes me as both dramatically gratuitous and disturbingly at variance with what is for the most part so faithful a transposition of Mann's original. ${ }^{63}$

Objections were often framed as moral responses to the scene's eroticism. While Malcolm Rayment suggested that "perhaps the worst [scene] was the seemingly interminable balletic scene at the end of the first act [which] became positively embarrassing with the girls fully dressed and the boys in little bathing trunks," Andrew Porter declared:

... my only serious reservations about the opera concern the Pentathlon that forms the climax of this suite [the Games of Apollo]. Right, that Aschenbach might have 


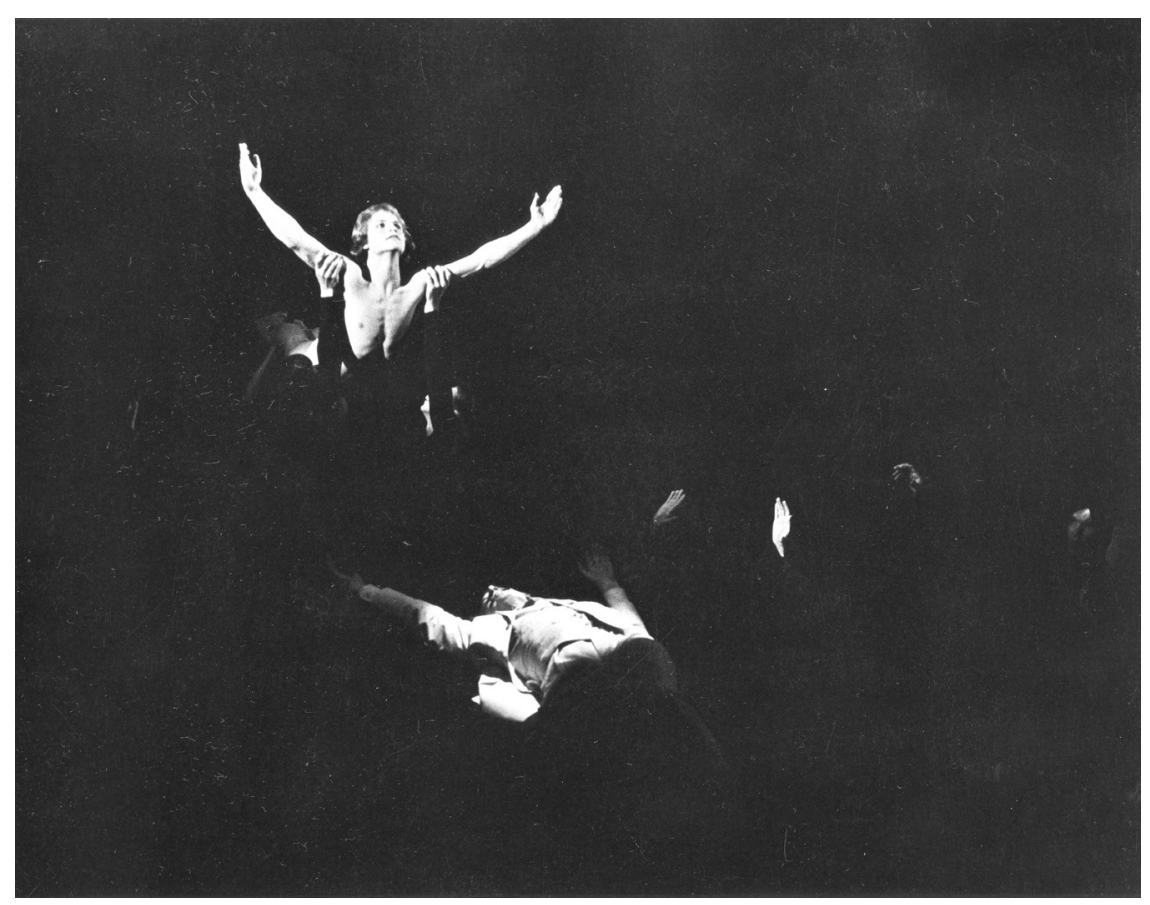

FIG. 16. Death in Venice (Act II, Scene 13)-Tadzio (Robert Huguenin), Dionysius's Followers and Aschenbach (Peter Pears). Snape Maltings, Suffolk, June 1973. Photo: Nigel Luckhurst. Image reproduced courtesy of the Britten-Pears Foundation.

a vision of Tadzio, victor in every event; unhappy, that the form it takes should suggest sports day at an English prep. school with a fond infatuated master looking on. ${ }^{64}$

In adding "I suspect, the introductory 'classical' dances . . . would probably have been enough to make the point," Porter belied his own aesthetic presumptions, implying that the mise-en-scène should be no more than a window into a more abstract domain, a principle often voiced in contemporaneous anti-operatic critiques. ${ }^{65}$ The problem with the "Games of Apollo" lasting longer than "necessary," then, was that the scene allowed spectators to notice the dancing bodies in front of them, compromising its symbolic function. Its dramatic "gratuitousness," "stasis," and "tediousness" were code for theatrical titillation. Peter Heyworth even went so far as to denounce the ballet as "contrived," "allow[ing] an element of divertissement that is quite foreign to the nature of Britten's score," a lapse equaled only by Aschenbach's dream in Act II (see Fig. 16): "A stagey device, even if it leads to a scene that, musically, is among the most gripping in the opera." 66

Such a comparison-between the "Games of Apollo" and Aschenbach's Dionysian dream - is particularly provocative because, for all that they purported to represent diametrically opposing aesthetics, there were several points-sore 
points indeed - of similarity: both incorporated Apollo or Dionysus into their cast of characters and featured a scantily clad dancer illuminated center stage, while the protagonist looked on from the periphery. ${ }^{67}$ While the genre's detractors would doubtless have interpreted the Act I finale's "lapse" into spectacle when it aspired to abstraction as a sign of failure-proof of opera's tendency to appeal to the body instead of the mind-we might prefer a more dialectical understanding, in keeping with Aschenbach's final thought speech:

For mark you, Phaedrus, beauty alone is both divine and visible; and so it is the sense way, the artist's way, little Phaedrus, to the spirit ... And by beauty we mean simplicity, largeness, and renewed severity of discipline; we mean a return to detachment and to form. But detachment, Phaedrus, and preoccupation with form lead to frightful emotional excesses, which his own stern cult of the beautiful would make him the first to condemn. So they too, they too, lead to the bottomless pit. ${ }^{68}$

In good Nietzschean fashion, Aschenbach's gloss on Plato's Phaedrus makes clear that Apollonian ideals of form and beauty strive to rise out of and fall back into Dionysus's sensual abyss. There can be no beauty without the senses, no order without chaos, no abstraction without immediacy. At once the most philosophically abstract and spectacularly visceral scene in the opera, "The Games of Apollo" bore this idea out in "operatic" fashion. When Death in Venice aspired to the ideal, it conjured up its conceptual opposite, deconstructing the very opposition that it stages. The stylization of the dances, the voyeuristic display of flesh, the ritualistic chorus, the musical climaxes and contrasts, the exotic orchestral and vocal colors (drums, wind machine, bells, and countertenor squealing high in his register) - all conjure up a phantasmagoric vision that both transcends and is pure theater.

\section{HEARING ABSTRACTION}

If bodily display was one reason why opera was regarded as suspect, the tradition of overwhelming and visceral music was another. As Bradley Pearson, Murdoch's fictional highbrow, put it:

I do not wish to deny that there are some people-though fewer than one might think from the talk of our self-styled experts-who derive a pure and mathematically clarified pleasure from medleys of sound. All I can say is that "music" for me was simply an occasion for personal fantasy, the outrush of hot muddied emotions, the muck of my mind made audible. ${ }^{69}$

After endorsing Bertolt Brecht's idea of music as a narcotic, seducing audiences with theatrical illusions and cheap thrills, Eric Bentley went even further, excluding music from the intellectual drama he famously championed:

Above all, music performs its dramatic functions very inadequately. Though Wagner and Richard Strauss have carried dramatic music to extraordinary lengths, they not 
only cannot, as the latter wished, give an exact musical description of a tablespoon, they cannot do anything at all with the more baffling world of conceptual thought. They cannot construct the complex parallels and contraries of meaning which drama demands. ${ }^{70}$

Such a dismissive view could apparently not go uncontested. This notion that "opera cannot qualify ideas," "paradigmatic" in the 1950s, compelled Joseph Kerman to pen his polemic Opera as Drama in $1956 .{ }^{71}$ In addition to being the most influential book on opera in the latter half of the century, establishing a set of criteria from which Anglo-American music critics could draw, Kerman's monograph laid bare the deep-seated ambivalence about the value and viability of the genre.

As many of Kerman's most often quoted aphorisms make clear, there is much in Opera as Drama to substantiate the view that in opera the body reigned supreme. In describing the music of Puccini and Strauss he draws heavily and disapprovingly on the language of sensual immediacy and physicality..$^{72}$ Among the specific musical characteristics associated with operatic immediacy was unmotivated lyricism, with Tosca's shepherd's folk song and church scene cast as mere pretexts for melody. ${ }^{73}$ Kerman's derogatory comments would soon be followed by Boulez's scorn at "voice for the sake of voice alone." 74 Not merely the primacy of melody but also the type of melody associated with opera attracted criticism. After describing Turandot as an aimless drift "from one pentatonic tune to the next, and from one sentimental phrase to its almost inevitable repetition," Kerman added: "Puccini clings to his limited ideas and repeats them protectively." 75 The constant and "indiscriminate" repetition laid bare Puccini's depraved priorities:

What mattered was not [Cavaradossi's] plight, but the effect it could make on the audience. Puccini's faint emotionality is directed out over the footlights . . Tosca leaps, and the orchestra screams the first thing that comes into its head; this loud little episode is for the audience, not for the play. ${ }^{76}$

Adorno, writing just a year before Kerman, agreed that these priorities compromised opera's dramatic integrity. ${ }^{77}$ Bending to the whims of "an audience that always wants to hear the same thing" instead of persuading its audience by its structural logic, opera seduced through grand rhetorical gestures and the repetition of cheap thrills and culinary moments. ${ }^{78}$

Although all three critics lamented the musical immediacy of popular opera in identical terms, their motivations were poles apart. While Adorno's comments were part of a general assault on the pretensions and delusions of the middle class, Boulez's critique formed the background to imagining a utopian future for the genre, one in which his own "unwritten opera" played a revolutionary role.79 Kerman's motivation was altogether different. Although his diagnosis of "flabby relativism" and "unintellectuality" in operatic culture might appear to be the epitome of anti-operatic discourse, it was actually intended as defense. Kerman's real antagonist was neither Puccini nor Strauss but rather those who regarded opera as 
a "low form of music" and "a low form of drama." ${ }^{\circ}$ In denigrating his bêtes noires, he sought to rescue others from similar charges: "between Verdi and Puccini, between Wagner and Strauss, lies the decisive gulf between art and sensationalism." ${ }^{11}$ Puccini and Strauss were, in other words, collateral damage in Kerman's fight to keep opera alive. Yet the rhetorical overkill with which the critic excoriated them suggests that cordoning them off from a more intellectual operatic tradition never convinced even him.

While the distinction between Puccini and Verdi, opera and drama, was occasionally cast as one of dramatic integrity, it was more often described in terms of musical form. ${ }^{82}$ According to Kerman, the most important way that opera could supply the kind of conceptual meaning denied to it by literary critics was through the "dramatic" potential of musical form: "Opera is a type of drama whose integral existence is determined from point to point and in the whole by musical articulation." ${ }^{83}$ Much as Boulez would later suggest "crack[ing] the discrepancy between symphonic music and operatic music," Kerman regarded organic development and symphonic form as solutions to the "problem" of operatic immediacy:

The new dynamic [symphonic] style made it possible to join together elements in essential contrast-soon treated as elements in essential conflict: abrupt changes of feeling were at first juxtaposed, then justified and developed until a final resolution lay at hand. Music in a word became psychologically complex. ${ }^{84}$

At least in Kerman's ears, dramatic music was distinguished from its "theatrical" counterpart by its integrating each moment into a dynamic whole. This allowed for a mode of reception in which the listener apprehended meaning by actively following the dialectical process of the unfolding musical form. While remaining keen that commentators avoid the kind of analytic reductionism associated with Alfred Lorenz-the "reductio ad absurdum of certain valid insights"-Kerman urged critics to direct audiences to symphonic opera, in which formal argument took precedence over rhetorical gesture and musical satisfaction could be rationalized as a hard-won activity of the mind. ${ }^{85}$

Kerman was just one of a number who defended opera through the moderate formalism that came to dominate Anglo-American operatic criticism in the period. It is no coincidence that, in scouring the repertoire for a recent opera whose "arresting" musical climaxes were underpinned by organic structure, Kerman should have pointed to The Turn of the Screw (1954). As we have seen, from this gothic drama onward, Britten's operas served as lodestars for the structural listening that Kerman sought to champion. Even mainstream critics were so taken with matters of musical technique that they became almost indistinguishable from musicologists, often discussing the same passages in almost identical terms. ${ }^{86}$

Yet even in this formalistic context, Death in Venice elicited responses that were remarkably attentive to matters of motivic unity and large-scale form. This was partly the work of specialist previewers who instructed critics and audiences 
alike on how to listen. In an introduction published in Opera magazine almost a month before the premiere, Peter Evans attributed the opera's dramatic power to hidden musical connections, demonstrating - with detailed musical examples and reductions - that its most compelling moments were derived from identical motivic cells ${ }^{87}$ Styling the opera as a discourse of musical motifs, he stressed the "characteristic refinements of musical detail and motivic chain" with which the composer had replicated the nuances of Mann's novella. In his Listener preview, Jeremy Noble did much the same:

What follows, then, attempts only to help the radio listener by bringing out some of the salient points in the music, and above all the images Britten has devised to embody the dualism that is the opera's central theme, a dualism of intellect and body, order and chaos, Apollo and Dionysus, life and death. ${ }^{88}$

Like Evans, Noble regarded the "density of the thematic relationships ... [as] the musical equivalent of Mann's deliberately claustrophobic style." ${ }^{89}$ Following the premiere, other critics were happy to get on board. Having suggested that the music's "ironies and thematic transformations are the musical equivalent of Mann's prose fabric," Patrick Carnegy praised the composer for "conjur[ing] deftly with a handful of closely related themes." ${ }^{\circ}$ For Porter, such "careful, deliberate use of leitmotif techniques" was not only symbolic of the intellectualism of Mann's novella but also crucial to the listener's experience: "as the listener grows familiar with the score, he begins to respond consciously to the cross-reference and relationships of the close-woven, many hued tapestry." ${ }^{11}$ Greenfield's review insisted that the music's emotional and symbolic content was supported by a larger sense of form:

The result over a very long span (nearly two and a half hours of music with only one interval) is an intensification of emotion, which firmly establishes the composer's right to impose operatic form ... Britten's music intensifies the symbolism on every level. For example, the arrival of the plague (symbol ultimately of Dionysiac indulgence) is felt subconsciously, long before the idea is made explicit in the text, through Britten's sinister use of the tuba in crawling bass figures ... Even a brief study of the score shows how subtle the web of musical motifs is, but even an unprepared listener will note the broad contrast of chromatic contortions (temptation music of every kind) set against the relative purity, often pentatonic, of the music of true beauty. ${ }^{92}$

Gillian Widdicombe, by contrast, opted for sheer denial, insisting that there was no "grand climax, finger-tip lyricism, and blatant emotions," much as we saw critics do with Peter Grimes. ${ }^{93}$ After concluding that "Death in Venice is one of those complex operas demanding and deserving time and thought for just appreciation [and] has nothing in common with the shallow, pretty-picture world of Visconti's film of the same name," Widdicombe exposed the stakes: the work had to be distanced at all costs from the "cheap" pleasures of operatic spectacle and film.

Yet while evaluations based on such restricted criteria do little justice to the opera's compelling theatricality, it is hard to deny that Death in Venice wears its 
formalism on its sleeve, right from the opening of the prologue. As audiences are plunged into the protagonist's philosophical monologue about the machinations of the intellect, Aschenbach's recitative traces a set of musical phrases that "calls attention," as Philip Rupprecht has shrewdly observed, "to its own rigor."94

Even as it retains a firm tonal orientation, Britten's opening (Ex. 21) thematizes serial construction by setting out its rows in clear and adjacent sets. The opening tetrachord $(\mathrm{F}-\mathrm{G}-\mathrm{F} \#-\mathrm{G} \#)$, for example, is immediately transposed up three semitones $(\mathrm{G} \#-A \#-A-B)$, before the final hexachord of the row is sounded $(\mathrm{B}-\mathrm{E}-\mathrm{D}-\mathrm{C}-\mathrm{D} b-\mathrm{E} b)$. In repeating the pattern in melodic inversion $(\mathrm{E} b-\mathrm{D} b-\mathrm{D}-\mathrm{C} ; \mathrm{C}-\mathrm{B} b-\mathrm{B}-\mathrm{A} ; \mathrm{A}-\mathrm{E}-\mathrm{F} \#-\mathrm{G} \#-\mathrm{G}-\mathrm{F})$, highlighted by a parallel inversion of register, the composer flaunts his motivic rigor. Such ostentation was a gift to commentators anxious to exorcize musical viscerality. Already in his preview, Evans observed that these opening tetrachords introduced the "plague" motif's major and minor thirds, setting in motion a symphonic thread that would run below the entirety of the opera's "surface." ${ }_{95}$ Porter likewise understood this "twelve-tone row" as signaling the beginning of the musical end by foreshadowing the motifs associated with the protagonist's eventual demise. ${ }^{96}$ Even the opera's most distinctive and unique moments, he insisted, could be traced back to these opening seeds. John Evans went even further:

If one is tempted to conclude that the twelve-note proposition and the modal resolution are unrelated strands of an eclectic score, one would be mistaken . . . The concept of modulation between the twelve-note proposition of the opening scene and the modal resolution of the opera's postlude acknowledges an extraordinary symphonic logic that permeates the score ... The opening twelve-note proposition in Death in Venice, while encapsulating the dramatic image of intellectual sterility within Aschenbach ("My mind beats on, and no words come"), initiates the central major/minor third motivic cell of the score and, as I hope to demonstrate, highlights the tonal polarities that place the Apollonian/Dionysiac conflict in context throughout the opera. ${ }^{97}$

Although written later, Evans's discussion sheds light on the widespread insistence that there was a "symphonic logic" running from the score's first note to its last. In stressing the long-term structural significance of the opening music, Evans was ruling out two possibilities: that it might be no more than a pictorial effect, illustrating intellectualism; and that it might represent the kind of eclectic dabbling in serialism that was just then being stigmatized as "amateurish."98

But a narrow focus on motivic connections served also to obscure more prosaic affective and rhetorical conventions. The most obvious way in which the prologue grabs attention is through a textural and dynamic crescendo; each new textural strand emerges from a different register, building the passage up like a large-scale arpeggio, while the harp's stretto glissandi further enhance dramatic suspense. This sense of "unrest" is heightened by underlying "Tristan" chord $(\mathrm{F}-\mathrm{A} b-\mathrm{B}-$ $\mathrm{Eb}$ ), whose dissonances remain unresolved at the end of each mini climax. Such 
ASCHENBACH
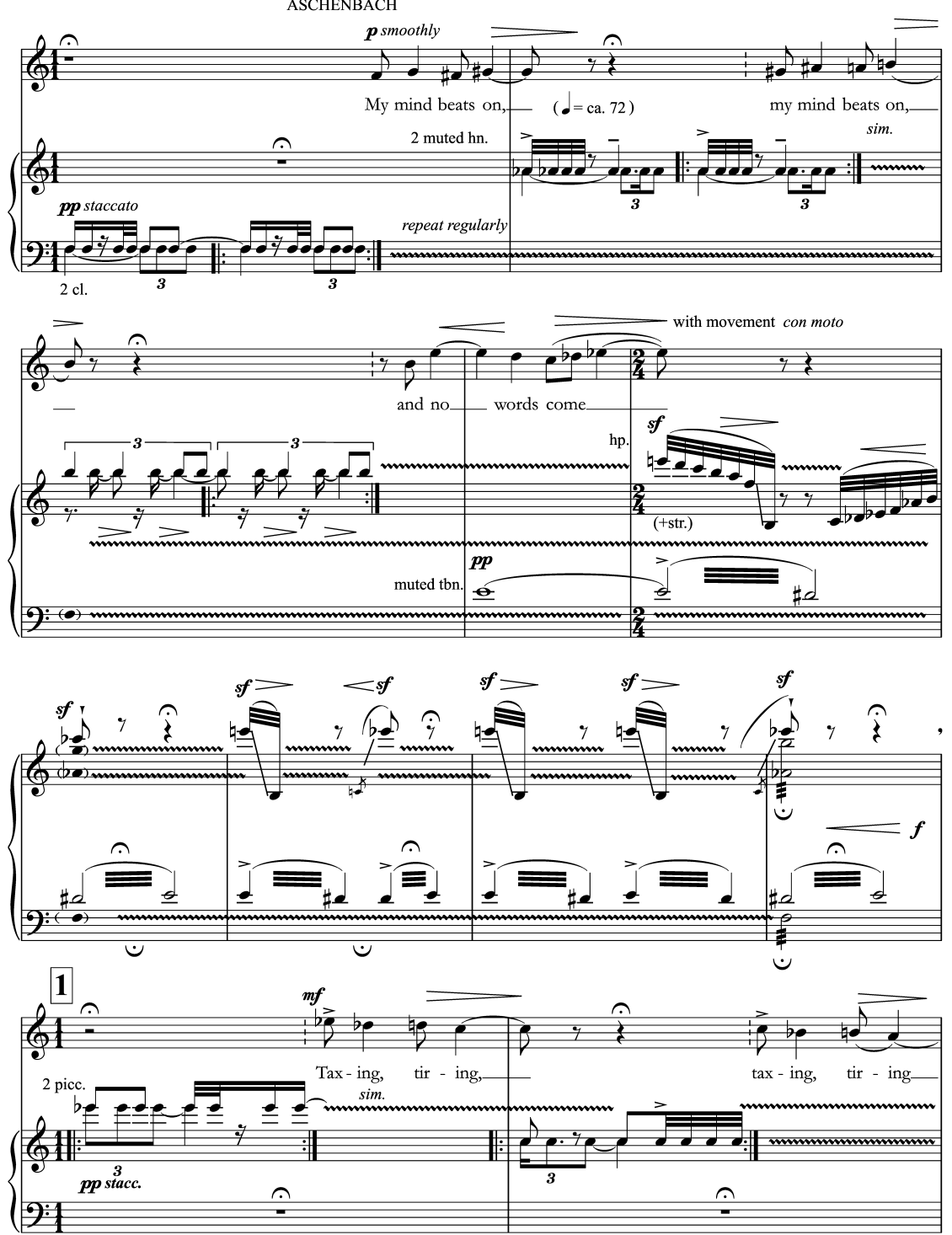

EX. 21. Death in Venice (Prologue)—"My Mind Beats On".

gestures of anticipation and frustration had the advantage of suggesting an overriding form even while relying on a relatively loose musical rhetoric.

The risk of falling on the wrong side of the great divide was all the more potent in the first act's theatrical conclusion (Ex. 22), which sports the kind of "grand 
(ob. hn. cl. all accel. freely)

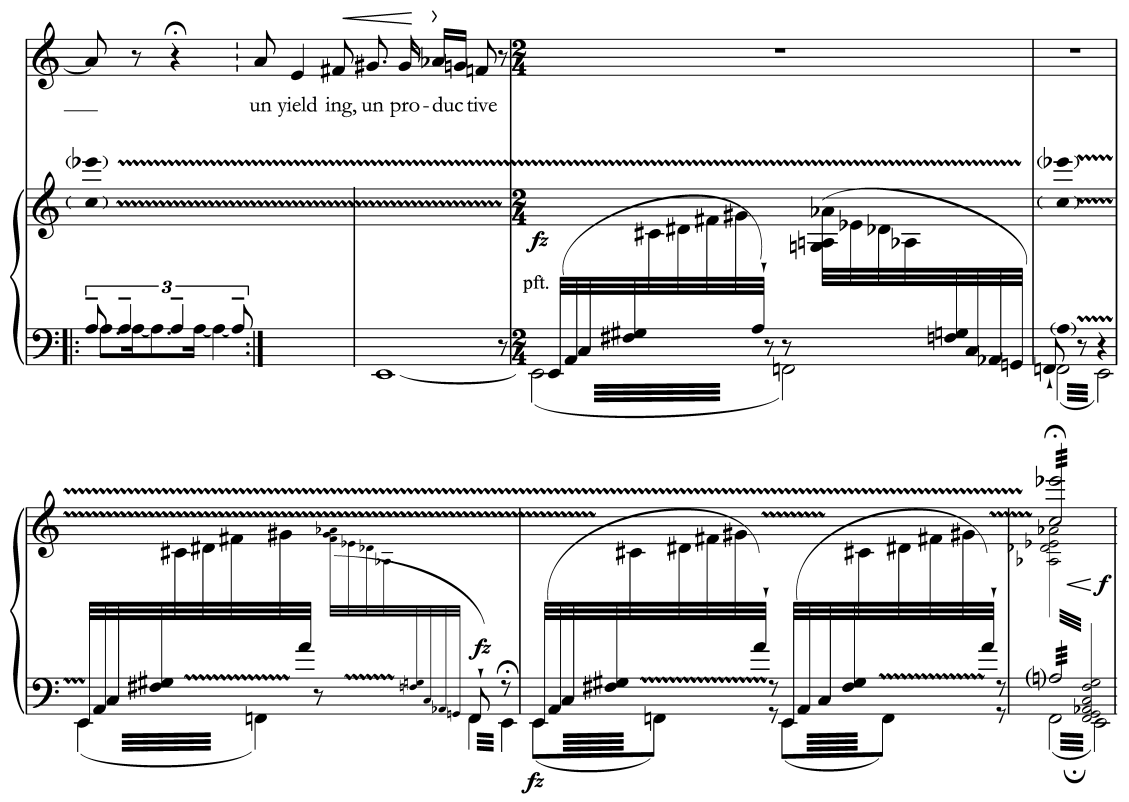

EX. 21 (continued).

climax" and "blatant emotion" that critics decried, and therefore denied. In musical terms, it might be described as a total crescendo-dynamic, rhythmic, textural, and registral-followed by a sudden, brass-punctuated climax accompanying Aschenbach's apparently wordless cry. Given opera's long-standing association with jouissance, we might well think of other terms here. The sustained bass drone, combined with the tenor's "almost spoken" descending third on the words "love you," perfectly captures a sense of postcoital relaxation. Indeed, this passage has unsurprisingly drawn comment in almost every discussion, for not only is it one of Death in Venice's capital moments, it also issues the most potent challenge to any notion that "the opera's abstractness neutralises the story's more volatile implications." ${ }^{99}$ Indeed, the passage's approximation of orgasm calls to mind the notion of "body music," coined by Daniel Albright in a discussion of A Midsummer Night's Dream (1960):

Oberon's cries are sublimated in all sorts of artful ways, through archaisms, through vocal lines that pretend to be instrumental lines, and so forth; but behind all these dissimulations there is something raw-not far from Peter Quint's Miles!, not even far from Bottom's hee-haw. Oberon's music, despite the self-conscious strangeness, its cerebral quality, is body music; if Bottom is the opera's chief ass, Oberon is the opera’s chief penis..$^{100}$ 
As Albright's irreverent metaphor makes clear, Britten often relied on more visceral levels of musical representation than critics were willing to admit. But, as Albright also notes, Britten's "body music" often contained the seeds of its own sublimation, in both text and music, almost as if audiences were encouraged to write off this "operatic" finale as ironic or insincere. It was an invitation critics were only too happy to accept:

Other stretches of music seem happy to stay on the level of, say, Puccini: and the closing line of Act One has Aschenbach proclaiming "I love you" to the receding figure of the boy, for all the world as if he were Don José singing his flower song to Carmen. Such banalities, however, seem sometimes to be planted deliberately in the score, so that Aschenbach can later comment self-critically on the state of his emotions. ${ }^{101}$

Those even less willing to admit the rhetorical grandeur of the opera's catharsis grounded the power of their reactions in structural "depths," not that they had to dig very "deep" to get there. In this respect, Evans once again led the way, rationalizing the significance of Aschenbach's outburst in terms of the "plague" motif and the major/minor third tension that flows from it. ${ }^{102}$

This tendency to focus on questions of long-term structure while blocking one's ears to the passage's immediate visceral dimensions persists even in the most recent scholarship. Listening for tonal progress as avidly as Evans had listened for motivic unity, Claire Seymour diverts attention from the music's bodily resonances to a more metaphysical meaning:

It rises chromatically from a low E, gradually spanning an octave, signifying the unstoppable advance of both the plague and Aschenbach's sickness ... The final phrase unequivocally establishes the E major tonality which Aschenbach has struggled to deny; but the final cadence is imperfect; suspended and unresolved: at the close of Act I spiritual transcendence remains a possible outcome. ${ }^{103}$

Ruth Sara Longobardi likewise advocates looking past immediate reactions at the deeper motivic significance of the protagonist's cry. After insisting "there has been little question as to the import of this passage," she offers an alternative to the supposedly common view: "The plague motive, because it derives directly from a Dionysian realm that functions beyond the protagonist's point of view, erodes the psychological realism of this moment, superimposing on Aschenbach's experience a layer of mythical significance." ${ }^{104}$ Far from being unusual, as she implies, her suggestion has been a standard rhetorical move.

Yet this is a move that conceals as much as it reveals. Most of the motivic references to which critics customarily appeal actually occur before Fig. 187 (see Ex. 22), a passage set apart from the climax (beginning at Fig. 188) by a shift in texture and motivic material, not to mention the pause (at the upbeat to Fig. 188). Moreover, the sense of harmonic release (at bar 16) can be viewed as being as much a result of the cessation of the local dissonances as the resolution of the large-scale tonal tensions that critics preferred to highlight. Even this marked "resolution" is 

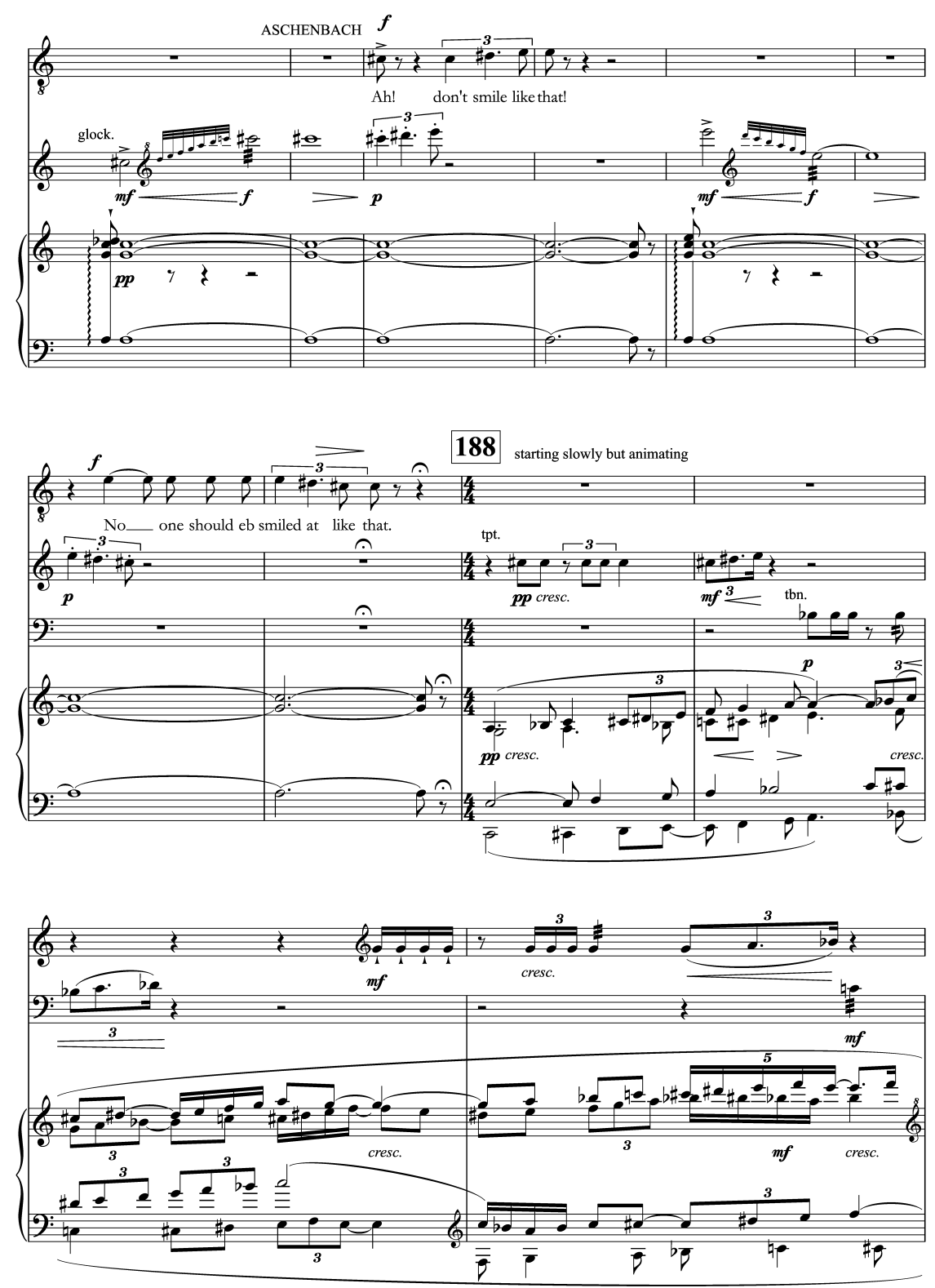

EX. 22. Death in Venice (Act I, Scene 7) - "I Love You". 

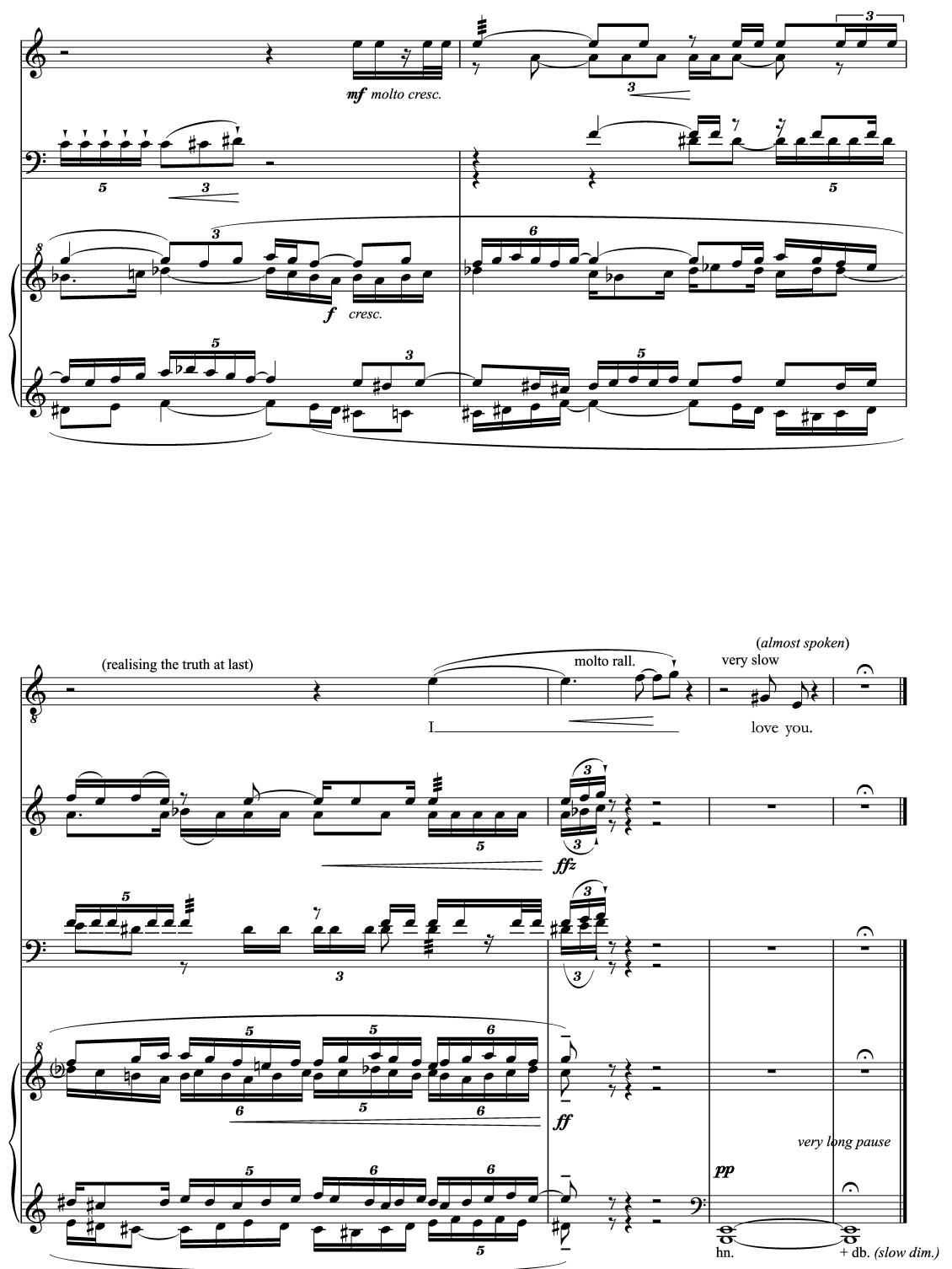

EX. 22 (continued).

hardly complete: while the horns and double-basses sound the root and fifth of the chord of an E major "tonic" in second inversion, the "almost spoken" utterance of Aschenbach lacks the audible strength to establish this key firmly. Indeed, given the speed of its buildup-from silence (just before Fig. 188) to a huge orchestral 
fortissimo (at bar 16) in the space of seven bars-the climax strikes a "performative" tone, creating the very tension that it appears to resolve. The accumulation of local dissonances thematizes large-scale tonal tension while the telescoping of textural lines provides the semblance of thematic density.

In an aesthetic context in which intellectual abstraction was valued over compelling immediacy, critics were granted a pretext to overlook other, less rarefied dimensions. The music obviously thrives on rhetorical juxtaposition and contrast; particularly within individual scenes, it is often constructed as a series of contrasting tableaux that approach the cinematic in the rapidity of their shifts. Not even the most rigid formalist could refrain from picking out outstanding musical "moments", even if they attributed their reactions to deep structure instead of compelling surface. Yet the opera's formal arrivals and rhetorical climaxes usually happened to coincide, suggesting that structural and atomistic modes of listening were two sides of the same coin, the former representing a sublimation rather than rejection of the latter. Far from a neutral mode of analysis, then, formalistic approaches to Death in Venice played into the broader aesthetic of sublimation sketched throughout this chapter, working alongside appeals to philosophical abstraction to redeem the opera's pleasures from the taint of the visceral.

\section{BOURGEOIS OPERA AND THE GREAT DIVIDE}

Opera has been in a precarious situation since the moment when high bourgeois society... ceased to exist .... At once barbaric and precocious, the newcomer who has not yet learned as a child to be bowled over by opera and to respect outrageous requirements will feel contempt for it, while the intellectually advanced public has almost ceased to be able to respond immediately or spontaneously to a limited stock of works, which have long since been relegated to the living-room treasure chests of the petit-bourgeoisie.

- THEODOR W. ADORNo, “BOURGEOIS OPERA," $1955^{105}$

In the final volume of his Oxford History of Western Music, Taruskin reflects on the "opera problem" that lies at this chapter's root. ${ }^{106}$ At a time when modernist polemicists were declaring culture to be "polarized to the point of crisis"-between an alienated avant-garde and a pandering mass culture-the spectacularly public genre was dismissed as decadent. In setting out the logic of the "great divide," Taruskin appeals principally to Clement Greenberg's essay "Avant-Garde and Kitsch," published in 1939: "The title," as he explains, "stated categorical alternatives. One could be avant-garde, or one could produce kitsch, mere pseudoart. There was no middleground." ${ }^{107}$ In the operatic sphere, however, Theodor Adorno's "Bourgeois Opera" has often been said to mark the mid-century battle lines. Indeed, for a number of scholars, Adorno's diatribe from 1955 stands as a shining example of modernist attempts to consign the opera to the "wrong" side 
of the great divide: to dismiss it as a cheap form of mass culture. ${ }^{108}$ With this in mind, Taruskin delineates the challenges that Britten operas pose: first, they kept the genre "viable through the leanest years of its existence, and prevented it lapsing into an exclusively 'museum' status"; and second, they remained popular with opera lovers while commanding the respect of critics "otherwise committed to modernism." ${ }^{109}$ In devoting a large portion of his chapter to Britten's awkward position, Taruskin sheds light on Death in Venice's stakes. In defending the work from the taint of immediacy, commentators were attempting to secure not just Britten's place on the "right" side of modernist historiography, but also the place of the operatic genre more broadly.

While this account highlights the importance of carving out space for seemingly paradoxical works like Death in Venice, it also demonstrates the difficulty in doing so. Despite setting out to show how Britten straddled the great divide, Taruskin's “standoff” between Britten's "Music in Society" and Elliot Carter's "Music in History" risks opening up the gap once again. Nor is this framework limited to the titles. In concluding his chapter with quotations from Britten's Aspen speech in 1964, spun as a "polemic against the other side of the mid-twentieth-century divide," Taruskin lays bare a thread that runs throughout his discussion of Britten's works. However, while he views Britten's operatic allegories as a way of serving society and renouncing modernist esotericism, we have seen that they often had quite the opposite effect. The real problem with presenting Britten as a populist foil to the contemporary avant-garde, however, is not simply that it glosses over these kinds of tensions and paradoxes, but that it reinforces the broader oppositions that this study has set out to challenge-between an art that serves society and one that scorns it.

If the complex case of Death in Venice demonstrates how Britten's oeuvre upended mid-century oppositions even as it drew on them, we might say the same of anti-operatic polemics like "Bourgeois Opera." We have seen throughout this study that the most forceful assertions of modernist oppositions often contain the seeds of their own deconstruction. In this respect, Adorno's and Boulez's diatribes were no exception. The historical distance may even allow us to recognize that their anxieties and complaints were shrewder and subtler than they at first appear. While scholars have often interpreted their attacks on opera as a straightforward product of snobbery-a dismissal of the genre as a cheap and indulgent progenitor of mass culture-Death in Venice may help us to tease out the deep-seated anxieties, tensions, and paradoxes that lurk between their lines.

In characterizing opera as "bourgeois," Adorno was, on the one hand, making a historical point: that the genre's inability to free itself from its origins in the "bourgeois era" had rendered it obsolete in the twentieth century. The period from which it hailed being one when "intellectual" concerns seemed to coincide with those of the people, opera now fell afoul of the great divide: "The esthetic conventions it rests upon, perhaps even the measure of sublimation it presupposes, can hardly be expected of the broad listening strata." 110 While the "unthinking" 
masses now turned to Hollywood for intoxicating spectacle, highbrows fancied themselves too sophisticated for opera's bargain-basement intellectualisms. It was in describing those who clung to opera throughout the twentieth century, on the other hand, that Adorno's use of "bourgeois" shifted from the largely neutral descriptor to a more pointed expression of social and aesthetic contempt: "Opera, more than any other form, represents traditional bourgeois culture to those who simultaneously fail to take part in that culture ... It is frequented by an elite that is no elite." 111 Much like Bradley Pearson, Adorno thought that the opera "problem" lay not just in the immediacy of its pleasures-as with mass culture-but also in the high-minded rhetoric with which it was rationalized. It was, in other words, one of middlebrow sublimation.

This problem was apparently only exacerbated by attempts to modernize, intellectualize, or otherwise repackage the genre-a paradox seen throughout Middlebrow Modernism. "Opera," Adorno insisted, "has reached the state of crisis because the genre cannot dispense with illusion without surrendering itself, and yet it must want to do so." "Forced attempts at innovation," he elaborated, were destined to fail, as making opera an honest genre would mean taking a Nietzschean hammer to its characteristic features. ${ }^{113}$ Or as reiterated by Boulez: "even if one announces a modern opera, that is really deception, because the word 'modern' must be dropped first if you are to join it to the word 'opera.' It cannot be modern because it is opera!"114 Whether serving as museums for a canon of tired masterworks or showcases for a "superficial modernism," opera houses were catering to "bourgeois" audiences eager to buy their way out of the great divide.

Such vitriol can be difficult to swallow; yet, when approached critically and historically, this discourse sheds light on Death in Venice and its reception. Adorno's discussion of "an elite that is no elite," eager to demonstrate its cultural distinction, accords with the defensive and esoteric rhetoric that permeated responses to the opera, as does his suggestion that this criticism could serve to sublimate the genre's less rarefied dimensions. Just as astute were Adorno's observations about how "bourgeois" operas encouraged this sublimation. In response to the vilification of operatic spectacle, he explained, directors and designers embraced a repentant aesthetic of scarcity on the one hand, and exaggerated stylization on the other. As we have seen, the original production of Britten's last opera shuttled back and forth between the austere minimalism of Aschenbach's monologues and the spectacular excess of the beach ballets. Bourgeois operatic music, according to Adorno, featured a similar mixture of asceticism and grand climax, sewn together with "thinly motivic materials." 115 These too were in Britten's final opera, and even bled one into the other, making the eclecticism all the more pronounced. It was precisely the motivic markers at the score's most rhetorically compelling moments that allowed critics to defend its "operatic" climaxes as intellectual rather than visceral. Affinities such as these marked Death in Venice as an archetypal "bourgeois opera," at once forbiddingly expensive and irredeemably cheap. 
In engaging with this view, it has not been my intention here-as elsewhere throughout this study - to pile on Death in Venice or its devotees but rather to encourage a more frank and nuanced discussion of the aesthetic values, tensions, and prejudices that shaped it. In diagnosing the failure of bourgeois opera as one of sublimation, critics like Boulez and Adorno highlighted its greatest strength: by moderating its intellectualism and asceticism with old-fashioned dramatic and musical spectacle, it offered a less abstemious form of modernism. As Begam and Smith have explained, opera's institutional strictures made it well suited to this task: "The operatic stage is a realm where function follows form more often than the other way around, and where avant-garde practices-twelve-tone composition, minimalist costuming, sets constructed entirely of light and show or else made shockingly au courant-tend to reify into mere gestures with peculiar rapidity." ${ }^{116}$ These tensions were built into the genre's aesthetic makeup. While the play of musical motifs allowed critics to disavow the grand operatic climaxes, the libretto offered an extra layer of apologetic intellectualism and rationalization. To judge from mid-century discourse, in other words, we might cast opera as the quintessentially middlebrow genre, capable of threatening modernism's oppositions. It is hardly surprising, then, that Boulez concluded his "operatic" diatribe by quoting the anxious dictum that appears near this study's opening: "Schoenberg was quite right," Boulez opined, "when he said, 'The middle road is the only one that does not lead to Rome," as if his Viennese idol had been discussing opera specifically. ${ }^{117}$

For all the talk of opera's death, the genre seemed to have cleared itself a busy middle road by the time Adorno and Boulez penned their polemics, enough so that they worried about bourgeois operas ruining the audience for genuine modern music. While Boulez associated this with Henze's irredeemably "compromised" commissions for the Hamburg Staatsoper, which threatened something of an operatic revival, Heather Wiebe has recently identified a comparable trend in British opera. ${ }^{118}$ Nor was the problem limited to opera. By the time Death in Venice reached the stage, many of those who had steered clear of the supposedly outdated genre were smuggling "operatic" theatricality and gesture into modernist compositions. In the realm of instrumental music, as Robert Adlington has pointed out, performative virtuosity, indeterminacy, and aleatoricism meant that even theoretically abstract modes of avant-garde composition "knock[ed] at the door of music theatre." 119 Much of the period's self-consciously anti-operatic music theater seemed to draw on the spectacular excess, stylization, or corporeality associated with opera. "While one must sympathize entirely," Rodney Milnes conceded in 1972, "with today's composers seeking a new name for the medium and jettisoning [opera's] excesses of duration, orchestral and choral forces . . . there is still a slight impression that they are stealing the emperor's clothes while pretending that they do not exist." ${ }_{120}$ From the wild Dionysian gestures of Birtwistle's Trageodia (1965) to the nude male dancer at the center of Maxwell Davies's Vesalii Icones (1969), Death 
in Venice was by no means the only work to foreground "operatic" corporeality amid a pretense of intellectual abstraction.

By now, however, it should come as no surprise that Adorno and Boulez were hardly exempt from these strictures. Less than a decade after threatening to blow up the opera houses, Boulez descended into the Bayreuth pit to conduct the "Ring of the Century." Even within his attacks in 1968, he let slip that his own operatic museum-should he ever get to choose one-would be as compromised and eclectic as the "musty old wardrobe" he detested. "Some Verdi," he conceded, "you are obliged to do, because Verdi very much belongs to history." ${ }^{121}$ Not even his more enthusiastic and daring selections were free of the taint of literal and musical spectacle: "C'est du Verdi seriel," one of his Darmstadt colleagues remarked of Boulez's beloved Moses und Aron. ${ }^{122}$ While Adorno had less to do with the genre in practice, his critical ambivalence was no less striking. At the height of integral serialism, he glanced back nostalgically to the "flamboyant" and "dramatic" style of Strauss, Schoenberg, and Berg. ${ }^{123}$ Elsewhere, his formalist defense of Wozzeck's "operatic" mode veered close to the kind of sublimation he loved to jeer at. ${ }^{124}$ One might even hazard that the reason why Adorno and Boulez regarded bourgeois opera as more pernicious than mass culture was that it mirrored their own ambivalent positions. For musical modernism was nothing if not a spectacular mixture of immediacy and abstraction. From some angles, the esoteric discourse of modernist circles-Darmstadt, IRCAM, even Boulez's imaginary theater-could look a lot like the pretentious nattering in the opera foyers, which modernists did their best to caricature. ${ }^{125}$ As Adorno pointed out, opera, at least since Wagner, had been a domain in which spectacle and form, body and mind, had interacted in destabilizing ways. Perhaps the problem with bourgeois operas like Death in Venice was not that they reconciled supposedly irreconcilable aesthetic categories. It was, rather, that they exposed modernism's own acts of sublimation, laying bare the precariousness of the great divide. 
